\title{
PASSENGER TRAVEL BEHAVIOR MODEL IN RAILWAY NETWORK SIMULATION
}

\author{
Ting Li \\ Eric van Heck \\ Peter Vervest \\ Jasper Voskuilen
Dept. of Decision and Information Sciences
RSM Erasmus University
P.O. Box 1738, Rotterdam,
THE NETHERLANDS

\author{
Freek Hofker \\ Marketing Research and Advice \\ Netherlands Railways \\ 3500 HA, Utrecht, \\ THE NETHERLANDS
}

\author{
Fred Jansma \\ Incontrol Enterprise Dynamics \\ 3606 AK, Maarssen, \\ THE NETHERLANDS
}

\begin{abstract}
Transportation planners and public transport operators alike have become increasingly aware of the need to diffuse the concentration of the peak period travel. Differentiated pricing is one possible method to even out the demand and reduce peak load requirement. An evaluation of the potential effectiveness of strategies directed to flatten the demand distribution requires an understanding of the underlying factors that drive travel behavior (e.g., time-shifting, route change, mode change) with regard to price and service. In this paper, we present a Passenger Railway Network Simulation model with the intention of linking supply and demand. The objective is to evaluate the differentiated pricing impact on the passenger travel behavior, and consequently on the overall network performance, both financially and operationally. This paper focuses on the design and modeling approach of the Travel Behavior Model.
\end{abstract}

\section{INTRODUCTION}

The past decade has witnessed an increased application of dynamic pricing in transportation industry, where firms use various forms of dynamic pricing to respond to market fluctuations and uncertainty in demand. Transportation planners and public transport operators alike have become increasingly aware of the need to diffuse the concentration of the peak period travel. Notably, dynamic pricing is one of the most preferred revenue management methods (Talluri and Van Ryzin 2004) to reduce the peak travel requirement and increase the capacity utilization. It has long been the tradition of transportation companies, especially airlines, to use the flexible pricing strategies to manage their perishable inventory efficiently. Argued by Boyer (1997), transportation companies are in an especially good position to engage in price discrimination. This is mainly because it is generally possible for the transportation companies to satisfy the characteristics that are common to the applications of the dynamic pricing ( $\mathrm{Li}$, van Heck, and Vervest 2006).

From a public transport operators' perspective, the challenge lies in evaluating the effectiveness of the dynamic pricing strategy on 1) demand (over time and space) and furthermore 2) on capacity utilization and revenue. This difficulty is caused by the lack of prompt and adequate customer response as a result of dynamic pricing implementation. This challenge requires an adequate model of demand as well as its dynamic interactions with the supply.

Computer simulation is an often-used methodology to study travel behavior as a cost effective alternative to field studies. For example, in the study of efficiency improvement of discriminatory toll of the San Francisco Bridge (Shmanske 1993), simulations are applied for two reasons. First, a simulation is necessary because solving consumer optimization problems analytically for this realistic case involves large problems that are beyond computational ability. Second, there are benefits concerning the magnitude of the price differences.

In our approach, we make two distinct steps to achieve the end. First, model the demand i.e. travel behavior. We define a parametric class of policies i.e. price, and build a simulation using a collection of micro-level behavior models. And second, simulate the interactions. We link demand simulation with the supply simulation, simulate the interactions and effects and use sensitivity information to optimize the policy parameters or performance metrics.

There are great challenges and questions posed by the design of passenger railway network (micro-)simulation. From a supply perspective, these include 1) the ability to create a large network that may encompass infrastructures (stations, tracks); 2) and the ability to lay time tables / train schedules over the railway networks. From a demand per- 
spective, the simulation requires 3 ) the ability to model an individual passenger with his/her characteristics and activities; 4) the ability to model the passenger behavioral choices before and/or while traveling, such as, mode choice, route choice, departure time choice; 5) the ability to track individual passenger's behavior changes under pricing policy influences; 6 ) and the ability to calculate the passenger delays as a result of the train delay.

The contribution of this paper lies in its ability to model the travel behavior of the passenger, as well as integrate passenger railway supply and demand. This provides the potential to incorporate advanced performance measures (e.g., network capacity utilization, passenger delay vs. train punctuality) into the organizational strategy as well as dayto-day operation.

This paper presents the design and modeling of these two phases of simulation, with the emphasis on the travel behavior model. In collaboration with Incontrol Enterprise Dynamics, we are currently developing and prototyping the simulation, partially fulfilling the research entrusted to RSM Erasmus University by Netherlands Railways.

\section{MOTIVATION AND MODELING APPROACH}

The objective of the passenger railway networks simulation we propose is to evaluate the effectiveness of strategies i.e. dynamic pricing on the railway network performance (financially and operationally). We distinguish two phases of this modeling effort. First, a model of the travel behavior -- activity-based travel behavior. This is to model the choice decision of a traveler on time-shifting, mode choice, departure time choice and route choice. Second, model interaction between supply and demand -- passenger railway networks simulation -- where we learn the behavioral impacts on the operational supply and vice versa. Before looking in more detail at the Travel Behavior Model, we first describe our motivation for the Passenger Railway Networks Simulation.

\subsection{Motivation for the Passenger Railway Networks Simulation}

Large infrastructure systems are often modeled using discrete event simulation models to enable evaluation of the future performance. Some examples of large infrastructure systems that have been modeled using discrete event simulation are railways for New York Freight Tunnel (Kulick, 2004), London Underground (Mayo, Dalton, and Callaghan, 2003), maritime infrastructure (Valentin, Steijaert, Bijlsma, and Silva 2005), railway infrastructure (Middelkoop and Bouwman 2001), North Sea channel (Hendrickx, Taeymans, and Bouwman 1998) and airplane runways (Holden and Wieland 2003).
Railway networks are complex systems that involve several thousands of passenger trains and millions of passenger journeys. These assets move quickly over networks composed of large sets of stations and tracks. Being one of the most utilized railway networks in the world, each day, Netherlands Railways (in Dutch Nederlandse Spoorwegen or $N S$ ) operates about 5,000 passenger trains on a network of 2,700 km for close to 325,000 train kilometres. There are about $1,000,000$ passenger journeys each day, with an average length of $44 \mathrm{~km}$. The crisscross network of 100 different train lines along nearly 400 stations makes sure that almost $80 \%$ of the passenger trips are made without transfer (Vromans 2005).

Considering the complexity of this system: the behavior of train operations and passenger movements involves a large number of input variables. The components of the system are coupled and the performance metrics are nonlinear. In addition, the operations are also constrained by governmental regulations and company specific policies. As a result, it is difficult to be confident in the results of an aggregate model, for example, where passengers are only segmented on their travel purposes (business, commuter and leisure). Therefore, there is a need to build a simulation model to capture and understand the complex and dynamics of passenger involved railway networks, and test the impact of various strategic and tactical decisions on the performance of the system both financially and operationally.

For a commercially operating railway company, providing a high level of service for the passengers is of utmost importance. This requires an adequate rolling stock capacity and high punctuality of the trains as well as of the passenger delays. These requirements could be better understood through simulating the supply (of complex railway network) and demand (of diversified passengers) interdependency and interaction for the following reasons:

- Dynamic pricing strategy's impact on the train yield. An effective pricing strategy, as a marketing instrument, could influence passengers' travel behavior, for example, making time-shift and/or route-shift during the travel. As a result, it consequently impacts the load factor of the specific trains passengers are taking. Train loading is, just as revenue, an important performance indicator of the railway operations. However, it is usually the concern of another department other than where the pricing policies are decided.

- Customer-centric timetable. At this moment, one of the key performance indicator for testing stability and robustness of the timetables is the train punctuality i.e. the percentage of trains that arrive within a certain delay. Focusing on the train punctuality, a very "good" timetable for the railway operators could, however, mean a very "bad" timetable for the travelers. Simply 
because some passengers would have to wait longer at the interchange. Copenhagen Urban Rail company (DSB) (Nielsen and Frederiksen, 2005) has defined passenger delays as the delays passengers experience when arriving at the destination compared to the arrival time in the planned timetable. According to Nielsen and Frederiksen (2005), train delay measurements tend to underestimate the delays passenger experience. If passengers transfer between lines, the situation becomes more complicated. Therefore, it is desired to design a customer-centric timetable, where passenger delays (or passenger punctuality) should be measured.

- Efficient resource allocation. Service personnel i.e. drivers and conductors play an important role in providing a high level service to the passengers. Efficient allocation of these staff resources requires knowledge of any possible changes on supply (capacity, delay, load factor) and demand (shifting behavior, passenger delay).

\subsection{Modeling approach of travel behavior}

We choose the activity-based microsimulation approach (Miller, 1996) to model the travel behavior of railway passengers. Here we briefly motivate our choice of this modeling approach.

Model of demand. As advances in revenue management continue, according to van Ryzin (2005), we are gradually seeing a shift in which models of demand are moving from product oriented to models of customer behavior. Instead of products, customers become the unit of demand. As a step in this direction, in this paper, we seek a solution to model behavioral choice of travelers under various dynamic pricing strategies. It is important to understand what influences their decision making, which is the key to building a better model of demand. As van Ryzin (2005) states that rather than asking "how much demand should we accept/reject for each product" as airlines used to do, it is now natural to ask "which alternatives should we make available to our customers in order to profitably influence their choices". These alternatives can be changes of price and/or schedule. Activity-based model. Activity-based models focus on the description of the organization of human activities in time and space. It is assumed the demand for travel is derived from the demand for performing activities at specific locations.

Microsimulation. According to Miller (1996), microsimulation has been accepted as a preferred approach to activity-based forecasting. Microsimulation model is formulated at the disaggregate or micro level of individual decision-making units, such as individual persons, households and vehicles. The strength of the disaggregate modeling approach as summarized by Miller (1996) are its power in representing: 1) the characteristics of the actors involved; 2) the characteristics of the choice context (in terms of the options involved, the constrains faced by the actors, etc.); and 3) any context-specific rules of behavior which may apply.

Travel agent. The unit of our simulation model is the individual passenger, who, similar to an agent, has the following properties (Wooldridge and Jennings 1995).

- Autonomous (operate without human intervention);

- Goal-oriented (act according to specific rules to accomplish a pre-determined goal);

- Asynchronous (operate independently);

- Reactivity (perceive the environment and respond to changes occur;

- Pro-activeness (have individual internal states and goals, acts through rules to meet its goals).

Validity and complexity. Using a microsimulation that models every passenger will inevitably increase the complexity of the simulation, comparing to the aggregated model that only simulates passenger flows. However, the simplicity comes with a price of low validity, that the models are not valid anymore for the questions we ask. Certain pricing strategies cannot be evaluated with the aggregated model. For example, "service-based" pricing, where people taking intercity trains are charged more than the ones taking stop trains. Passenger might react differently to this policy depending on his travel purpose and travel distance. Therefore, we would have to model passengers in groups: leisure travelers who travel long distance between A and B with intercity trains are modeled in one group. When the group size goes to very small, we get the model of single traveler case.

\section{SIMULATION FRAMEWORK}

An overview of the passenger railway network simulation is illustrated in Figure 1. Supply simulation module and demand simulation module form the core of the Passenger Railway Network (Micro-) Simulation.

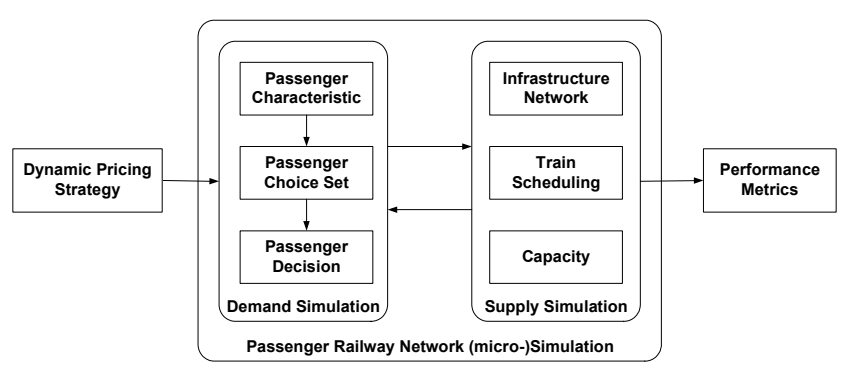

Figure 1: Passenger Railway Networks (Micro-) Simulation 


\subsection{Supply simulation}

The supply simulation module consists of infrastructure networks (e.g., stations, tracks), train scheduling (time table and delays), and train capacity. Designed and implemented by Incontrol Enterprise Dynamics, a simulation tool called SIMONE (Simulation MOdel of NEtworks) is currently being used by ProRail, the Dutch railway infrastructure capacity planner, and NS. Detailed description of this model can be found at (Middelkoop and Bouwman 2001).

\subsection{Demand simulation}

Demand simulation module simulates the travel decision-making process of the railway passengers, who respond to transport operator policy changes (e.g., dynamic pricing strategies) and could make decisions before/while traveling. Through literature study and discussion with the field experts, we outline the requirements for a successful implementation of our travel behavior simulation as follows:

- Traveler is modeled as an individual agent, who has certain characteristics and travels according to his activity schedule.

- Traveler plans his journey based on a set of available options. These options include both public and private mode of travel. Traveler rationality is considered.

- Traveler can respond to policy changes (e.g., price increase at a particular hour) based on pre-defined decision rules.

- Travel demand between origin-destination should incorporate the variability elements like seasonality and variations in the level of demand over different timeof-day and day-of-week.

- Traveler makes decisions based on a utility maximization choice. Utility is the combination of passenger fare, maximum willingness-to-pay, replaning disutility, etc., which will be discussed in the next section.

\subsection{Dynamic pricing strategy}

There are many forms of dynamic pricing used by different industries (Talluri and Van Ryzin 2004). Considering the characteristics of domestic railways, however, only a number of dynamic pricing strategies are considered as relevant choices ( $\mathrm{Li}$ et al. 2006). These policies are summarized as follows and will be used in the scenario experiments:
- Time-based pricing (time-of-day): price varies according to different time-of-day (e.g., lower price before 7:00; higher price between 7:00-9:00).

- Time-based pricing (day-of-week): Weekday vs. weekend; Different day-of-week price.

- Spatial-based pricing (regional-based): Randstad (a high density area on the west of the Netherlands) and non-Randstad.

- Spatial-based pricing (route-based): price varies according to the utilization of the specific route.

- Service-based pricing (class-based): $1^{\text {st }}$ and $2^{\text {nd }}$ class.

- Service-based pricing (different train types): price varies for international train, intercity and stop train.

- Profile-based pricing (travel in group): for example, travel in group is cheaper.

- Or the combination of different pricing policies.

\subsection{Performance metrics}

As a general measure, we develop the following metrics to evaluate the performance of supply and demand of the railway network. More detailed metrics in regard to each type of dynamic pricing will be developed in the later phase.

Table 1: Performance Metrics

\begin{tabular}{|l|ll|}
\hline \multicolumn{1}{|c|}{$\begin{array}{c}\text { Metric } \\
\text { category }\end{array}$} & \multicolumn{1}{c|}{ Metrics } \\
\hline $\begin{array}{l}\text { Supply } \\
\text { (train } \\
\text { operation) }\end{array}$ & - $\begin{array}{l}\text { Network capacity utilization (load } \\
\text { factor) }\end{array}$ \\
& $\begin{array}{l}\text { Spread in train loading (passenger } \\
\text { distribution) }\end{array}$ \\
& - $\begin{array}{l}\text { Peak and average load } \\
\text { Train trips per day }\end{array}$ \\
& - $\begin{array}{l}\text { Cost (or distance) per day per train } \\
\text { Repositioning distance per day per } \\
\text { train }\end{array}$ \\
\hline $\begin{array}{l}\text { Demand } \\
\text { (passenger } \\
\text { travel) }\end{array}$ & $-\begin{array}{l}\text { Revenue (distance) per day per train } \\
\text { Passenger km per train }\end{array}$ \\
\hline
\end{tabular}

\section{PASSENGER TRAVEL BEHAVIOR MODEL}

The travel choice process (e.g., activity scheduling, implementation and rescheduling) is one of the key components within the activity and travel decision framework as depicted by Bowman and Ben-Akiva (1996). They argue that this process could be better modeled with understanding of general theory on how people make choices. Choice theory suggests that decisions can be viewed as a two stage process of choice set generation and choice. Individuals use coping mechanisms (Bowman and Ben-Akiva 1996) in order to make decisions with limited resources when the alternative set is as large and complex as that of the activity and travel scheduling decision. 
Simulations are systems of sequential decision rules predicting decision process outcomes. There are a number of simulations focusing on choice set generation (Bowman and Ben-Akiva 1996), while others emphasize on the choice (Carrier 2003). Among others, the Passenger Choice Model developed by MIT and seven leading airlines (Carrier 2003) appears to be serving a similar objective as the one we have. This model is developed to reproduce how hypothetical air travelers choose among different airlines, flight schedule and fare class products.

Based on this model and extended with our context specific requirements, we have designed our Travel Behavior Model as illustrated in Figure 2. It consists of three main components, namely, passenger disposition, passenger choice set and passenger decision.

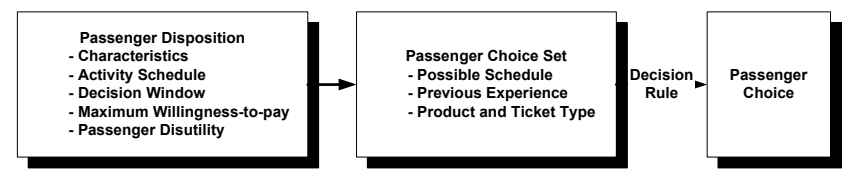

Figure 2: Elements of Travel Behavior ModelPassenger disposition

The model starts with assigning each passenger a set of characteristics, which will have major influences on the travel choices, to present his preferences. These could include age, income, education, car ownership / availability, etc. Because travel demand is derived from activity demand, a passenger is then given a series of activities to conduct, which we call activity schedule. The activity schedule consists of activity location, timing, duration, and purpose, from which we can infer travel frequency, travel distance, travel purpose and origin-destination. The activity schedule is then used for journey planning, which is elaborated in more detail in the next section.

Some passenger characteristics could have significant influence on the travel choice. For example, travelers could be divided into three segments based on their travel purposes between each origin-destination pair: commuters, leisure travelers and business travelers. Thus, travelers in different segments will have different behavioral assumptions when facing different alternatives. For example, leisure travelers would be more flexible in time-shifting than commuters who are expected to be at work at a specific time.

In addition to the characteristics and activity schedule, each traveler also gets assigned a decision window, a maximum willingness to pay, and a set of passenger disutility.

Decision window. Because part of the interest of this research is on the effect of the price strategy on the passenger behavioral change, it is important to understand how people would react to, for example, time-based price differentiation. For time-based price policies, for example, introducing an "afternoon-peak price", meaning passengers who travel between 16:00-18:00 pay more for the journey. In this case, there are four options passengers would choose:

1. Time-shifting: shift their departure time to before 16:00 or after 18:00 in order to avoid the "afternoon-peak price";

2. Mode-change: leave railway and change to private transport (e.g., car);

3. No change, accept the price increase;

4. Stop travel: it is more likely to happen for leisure travelers).

There are three factors that have strong influences on the time shifting nature of the passenger behavior: price differences, departure time (time-of-day), and schedule tolerance. Schedule tolerance indicates how much time shifting a passenger could afford. The value of schedule tolerance is given randomly to each single traveler but depends on travel purpose and travel time. A similar analysis is also made for route shifting when spatial-based pricing strategy is introduced.

Maximum willingness-to-pay. Each passenger is also assigned a maximum willingness-to-pay, which represents the maximum amount this passenger is willing to pay for his journey. And it depends heavily on the travel purpose of the passenger. Business travelers tend to have higher maximum willingness-to-pay than the leisure travelers. Certain passenger characteristics also play an important role in determining the maximum willingness-to-pay. For example, travelers with higher income would have higher willingness-to-pay than the people that have low income.

Passenger disutility. Disutility is associated with price restrictions and other disutilities, such as replanning disutility and path quality. Usually a certain price is given with some restrictions. For example, a group price requires a group of more than 4 people traveling together. Replanning disutility occurs when passengers have to make behavioral changes, such as time-shifting, route change or even mode change, in order to benefit from lower prices. This disutility is different from commuters to leisure travelers to business travelers. The quality of the path depends on the factors such as number of transfers, transfer waiting time, in-vehicle time and total travel time.

\subsection{Passenger choice set}

Once the passenger disposition model has assigned the characteristics, the activity schedule, the decision window, the maximum willingness-to-pay and the passenger dis- 
utility, the model will define the passenger choice set.

Possible schedule. A number of journey options are generated for each single passenger based on required departure time, arrival time, and origin-destination. The option contains transport modes, routes and vehicle types (e.g., intercity train, stop train).

Previous experience. A key advantage of our model is including passengers' previous experience (or "soft component") into the choice process. In reality, passengers decision-making is influenced by the crowdness of the train, comfort i.e. seat availability, punctuality of service, and safety.

Product and ticket type. It is important to note that, considering the current fare structure, the passengers' product choice and the ticket type choice influence their decision for traveling and travel behavior. It is important to distinguish these two concepts. We use product to describe something that provides a discount on future journeys. For example, reduction card that provides discounts on a range of journeys over a period of year; all forms of season tickets that provide a "free travel" on a specific journey for a given period of validity. Ticket type is mainly referring to the single and return ticket. The decision making of purchasing a product or a ticket varies. The decision of buying a specific product type takes into account the likely use of the railway network over a future period of time, while purchasing a certain ticket type usually happens right before the traveling, and is determined by what type of product a person has.

\subsection{Passenger decision}

Given the passenger disposition and the passenger choice sets, each single passenger follows his decision rule to make choices on departure time, route, mode and fare. The decision rule is to minimize generalized cost of travel. Generalized cost is calculated based on various assigned factors: characteristics, activity schedule, price, maximum willingness-to-pay, disutility, etc.

\subsection{Passenger travel tasks}

As part of the modeling effort, we model a series of tasks a passenger needs to conduct before/while traveling:

- Construct activity schedule: produce a daily activity schedule (a series of activities with time, location, duration, etc.) for a passenger to execute.

- Execute activity schedule: pick up one activity from the activity schedule and start planning a journey if traveling is required (e.g., the next activity is not at the same location as the last activity).
- Plan a journey: search for a set of alternative journey options.

- Select a journey: choose a journey (among possible options) based on a set of decision rules.

- Execute a journey: execute a journey on a trip-by-trip base (a journey consists of one or more trips).

Figure 3 is an illustration how a passenger "plans a journey" (using the activity diagram). Journey planning is the search for a set of alternative journeys from which one is chosen. This happens during the execution of the activity schedule when a journey is encountered. We distinguish two types of search through the alternative journeys. One is the rational search, where decisions are made by going through all the possible alternatives. For example, using a route planning tool (e.g., website) to find a set of options. And the other one is bounded-rational search, or what we call heuristic search. This search is fundamentally based on the prior journeys made by the decision maker. As an illustration, we describe "plan a journey" in an activity diagram in Figure 3.

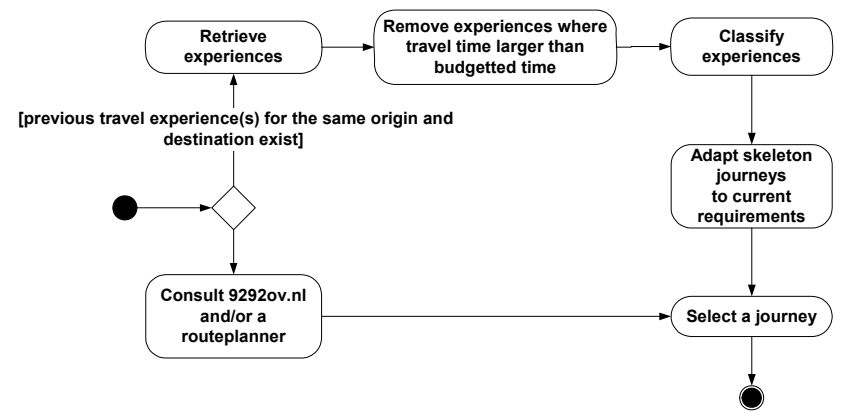

Figure 3: Activity diagram—Journey Planning

\section{DISCUSSION}

In this paper, we propose a Passenger Railway Network Simulation that is suitable for policy evaluation (e.g., dynamic pricing strategies) on the system performance (financial and operational). The focus is on the design and modeling approach of the Travel Behavior Model. Using an activity-based approach, this model represents the choice process of passengers on time-shifting, route choice, departure time choice and mode choice, under different pricing strategies.

Simulation input data. Considering the number of factors we model, undoubtedly, the proposed simulation requires large and accurate data as input to make it sound and realistic. Therefore, we will use a number of $N S$ surveys that describe the characteristics of railway passengers as inputs for the Travel Behavior Model. In addition, the parameters concerning trade-offs between for example price and time will be calibrated with data on behavioral 
change under different pricing policies that obtained with additional marketing research.

Data accuracy. With the availability of the smart card data in the near future, updating and synthesizing the simulation with the real-time passenger information would become a reality.

Validation. Our simulation will be executed using actual parameters of the current state of the railway network. The validity of the simulation will be evaluated by comparing the performance metrics from the simulation and the ones from the actual state of the network. However, a detailed discussion on the validation is out of the scope of this paper.

Currently we are developing and prototyping the simulation and we believe that we will be able to share some preliminary results during the conference presentation of this paper.

\section{REFERENCE}

Bowman, J. L., and M. Ben-Akiva (1996). Activity Based Travel Forecasting. Paper presented at the Activity-Based Travel Forecasting Conference.

Boyer, K. D. (1997). Principles of Transportation Economics: Addison Wesley Longman, Inc.

Carrier, E. (2003). Modeling Airline Passenger Choice: Passenger Preference for Schedule in the Passenger Origin-Destination Simulator (PODS). Massachusetts Institute of Technology.

Hendrickx, F., B. Taeymans, B., and M. Bouwman (1998). A vesselt traffic simulation model for the north sea channel area. PORTS.

Holden, T. C., and F. Wieland (2003). Runway schedule determination by simulation optimization. Proceedings of the 2004 Winter Simulation Conference.

Kulick, B. C. (2004). The use of simulation to support major transportation planning decisions. Proceedings of the 2004 Winter Simulation Conference.

Li, T., E. van Heck, and P. Vervest (2006). Yield Improvement with Smart Card Adoption in the Dutch Travel Industry. Paper presented at the ENTER 2006 Global Travel and Tourism Technology and eBusiness, Lausanne, Switzerland.

Mayo, D. D., W. J. Dalton, and M. J. Callaghan (2003). Steering strategic decisions at London underground: Evaluating Management Options with System Dynamics. Proceedings of the 2004 Winter Simulation Conference.

Middelkoop, D., and M. Bouwman (2001). Simone: large scale train network simulations. Proceedings of the 2001 Winter Simulation Conference.

Miller, E. J. (1996, June 2-5, 1996). Microsimulation and Activity-Based Forecasting. Paper presented at the Activity-Based Travel Forecasting Conference.
Nielsen, O. A., and R. D. Frederiksen (2005). Modelling train passenger delays. In The Reliability of Traveling and the Robustness of Transport Systems.

Shmanske, S. (1993). A simulation of price discriminating tolls. Journal of Transport Economics and Policy, 27(3), 225-235.

Song, C. M., S. Havlin, and H. A. Makse (2005). Selfsimilarity of complex networks. Nature, 433(7024), 392-395.

Talluri, K., and G. J. Van Ryzin (2004). The Theory and Practice of Revenue Management. Massachusetts, USA: Kluwer Academic Publishers.

Valentin, E. C., S. Steijaert, R. A. Bijlsma, and P. Silva, (2005). Approach for modeling of large maritime infrastructure systems. Proceedings of the 2005 Winter Simulation Conference.

van Ryzin, G. (2005). Models of demand. Journal of Revenue and Pricing Management, 4(2).

Vromans, M. J. C. M. (2005). Reliability of Railway Systems. Ph.D. Dissertation: RSM Erasmus University, Netherlands.

Wooldridge, M., and N. R. Jennings (1995). Intelligent agents: theory and practice. Knowledge Management Review(January), 1-62.

\section{ACKNOWLEDGMENT}

This research is supported by Incontrol Enterprise Dynamics and Netherlands Railways (NS). We gratefully acknowledge the help of Louis Schijve and Jan Thiermann from Incontrol Enterprise Dynamics, and Theo van der Star and Paul Rooijmans from NS. We further thank the helpful comments and insights of Niels Lang in preparation of this manuscript.

\section{AUTHOR BIOGRAPHY}

TING LI is a Ph.D. candidate at RSM Erasmus University. Her research focuses on the network structure impacts on the network performances. Specifically, she investigates how the dynamic pricing strategy could affect the travel behavior and consequently impact the network yield, given the capacity constrained network. Her email address is <tli@rsm.nl>.

ERIC VAN HECK holds the Chair of Information Management and Markets at RSM Erasmus University, where he is conducting research and is teaching on the strategic and operational use of information technologies for companies and markets. He is best known for his work on how companies can create value with online auctions. His email address is <evanheck@rsm.nl>.

PETER VERVEST is a professor of business telecommunications at RSM Erasmus University, and partner of D- 
Age, counselors and investment managers. He specializes in the application of telecommunications for business networking and decision-making and focuses on the development and management of "smart business networks". His email address is <pvervest@rsm.nl>.

JASPER VOSKUILEN is a master student in business administration at RSM Erasmus University. He holds both BSc. in information science and BSc. in electrical engineering. His e-mail address is $<j$ voskuilen@rsm.nl>.

FREEK HOFKER is a senior project manager at the department of marketing research of NS Commercial (Neth- erlands Railways). He specializes in transportation and marketing research and focuses on the impact of marketing strategy and railway planning on the demand for railway transportation. His email address is <freek.hofker@ ns.nl>.

FRED JANSMA is head of development at Incontrol Enterprise Dynamics. He is responsible for the development of the simulation platform Enterprise Dynamics with which this research study is performed. His email address is $<$ Fred.Jansma@EnterpriseDynamics.com>. 